\title{
Gestão de resíduos eletrônicos: estudo de caso em uma organização militar de São Gabriel/RS
}

\author{
Electronic waste management: case study on a military organization of São Gabriel /RS
}

\author{
Jaqueline de Freitas Quintana e Luciana Borba Benetti \\ Universidade Federal do Pampa, Campus São Gabriel, RS, Brasil \\ jakquintana@yahoo.com.br; lucianaborbabenetti@gmail.com
}

\begin{abstract}
Resumo
O artigo aborda a análise da destinação dos resíduos eletrônicos na organização militar $13^{a}$ Companhia Comunicações Mecanizada e tem como objetivo geral caracterizar os procedimentos utilizados no gerenciamento dos resíduos eletrônicos. O referencial teórico abordou os conceitos de resíduos eletrônicos, a situação destes resíduos no Brasil, consequências do descarte incorreto e possíveis soluções para destinação final. Foi realizado um estudo de caso, onde os dados foram coletados por meio de observação direta no local e aplicação de entrevista semi-estruturada com o gestor ambiental da organização. A pesquisa proporcionou compreender a realidade do processo de gerenciamento dos resíduos eletrônicos: computadores e seus periféricos. Primeiramente buscou-se identificar quais os tipos de resíduos eletrônicos existentes e posteriormente foi analisada a destinação final. Como resultado da pesquisa constatou-se que a organização possui um número elevado de equipamentos obsoletos e está preocupada com o descarte correto e, devido a isso, possui um sistema de gerenciamento. Através do Plano de Gestão Ambiental foi possível fazer o descarte correto dos resíduos eletrônicos, sendo que no ano de 2014 os resíduos foram encaminhados à Empresa Químea e neste ano foram encaminhados para depósito da Prefeitura Municipal, onde esta se encarregará de dar a destinação final adequada aos resíduos.
\end{abstract}

Palavras-chave: Resíduos Eletrônicos. Organização Militar. Gestão Ambiental.

\begin{abstract}
The article deals with the analysis of the disposal of electronic waste in the military organization 13th Mechanized Communications Company and its overall objective to characterize the procedures used in the management of electronic waste. The theoretical framework deals with electronic waste concepts, the situation of waste in Brazil, incorrect disposal of the consequences and possible solutions for final disposal. A case study where the data were collected through direct on-site observation and application of semi-structured interviews with the environmental manager of the organization was held. The research provides understand the reality of the process of managing electronic waste: computers and their peripherals. First we tried to identify which types of electronic waste and the disposal was subsequently analyzed. As a result of research it was found that the organization has a large number of obsolete equipment and is concerned about the proper disposal and, because of this, has a management system. Through the Environmental Management Plan was possible to make the proper disposal of electronic waste, and in 2014 the remains were sent to the Company Quimea and this year were directed to deposit the City Hall, where it will be responsible for giving adequate final destination waste.
\end{abstract}

Keywords: Electronic waste. Military organization. Environmental Management. 


\section{Introdução}

A crescente demanda por equipamentos eletrônicos mais modernos e eficientes tem contribuído para o número elevado de resíduos eletrônicos descartados de forma incorreta e gerando assim um problema ambiental grave, pois o acúmulo desse tipo de lixo, sem destinação correta provoca sérios riscos ao meio ambiente e em alguns casos esses riscos podem ser irreversíveis (SELPIS; CASTILHOS; ARAÚJO, 2011).

O crescimento dos resíduos eletrônicos é decorrente do avanço tecnológico dos últimos anos. Aumentando significativamente a quantidade e diversidade dos equipamentos, fazendo com que a população e empresas descartem seus equipamentos com mais frequência, e por isso, eles tornam-se obsoletos mais rapidamente. Estes resíduos hoje têm percentual significativo no lixo descartado ao meio ambiente (SCHONS, 2012).

O resultado disso é um enorme aumento nos resíduos tecnológicos para descarte, tanto nas residências como em instituições públicas e privadas. Esses resíduos, comumente designados de lixo eletrônico ou resíduo eletrônico são compostos por diversos materiais distintos: plásticos, metais, vidro, entre outros. Isso leva à problemática do reuso ou reciclagem, tendo em vista que certos componentes necessitam de tecnologias ainda não presentes no Brasil para a separação, tratamento e correta destinação (NATUME et al, 2011).

A rápida obsolescência dos equipamentos eletrônicos, a falta de legislação e fiscalização sobre sua destinação correta tem contribuído para que equipamentos ou suas partes sejam descartados como lixo comum, sendo que estes resíduos contêm contaminantes prejudiciais à saúde e ao meio ambiente como metais tóxicos e diversos outros materiais que não são biodegradáveis não podendo, assim, serem descartados como lixo comum (ALMEIDA et al, 2015).

O resíduo eletrônico é um problema das empresas públicas, empresas privadas, governo e sociedade. Todos devem assumir compromisso quanto ao cumprimento do ciclo de vida desses equipamentos, ou seja, todos são responsáveis pelo bem adquirido desde a compra até seu descarte. Todo equipamento eletrônico um dia será descartado, porém deve haver o conhecimento que o descarte do produto não significa o seu fim, visto que os mesmos são compostos de uma grande variedade de componentes (SILVA, 2010).

Com base no exposto acima surge o seguinte problema de pesquisa: Como é feito o gerenciamento do descarte dos resíduos eletrônicos na organização militar $13^{\mathrm{a}}$ Companhia de Comunicações Mecanizada e o que poderia ser feito para melhorar este gerenciamento e, assim, minimizar os efeitos negativos causado ao meio ambiente pelo descarte incorreto destes tipos de materiais?

O presente estudo tem como objetivo geral caracterizar os procedimentos utilizados no gerenciamento dos resíduos eletrônicos na organização militar $13^{\mathrm{a}}$ Companhia Comunicações Mecanizada, expondo e levantando possíveis problemas neste processo. Sendo que para atingir o objetivo geral foram definidos três objetivos específicos, que são: a) Caracterizar o resíduo eletrônico, assim como as consequências do descarte incorreto. b) Identificar como é feito o descarte de resíduos eletrônicos pela organização militar $13^{\mathrm{a}}$ Companhia de Comunicações Mecanizada. c) Recomendar ações de melhoria no gerenciamento do descarte dos resíduos eletrônicos na organização militar.

A escolha do tema é devido ao fato da necessidade de uma gestão adequada com a realidade da organização, visto que é produzido um número elevado de resíduos eletrônicos e estes devem ser descartados de foram correta. Sendo assim, busca-se com este artigo analisar as questões relacionadas ao resíduo eletrônico, focando na sua destinação correta, analisando o gerenciamento praticado atualmente e sugerindo ações de melhoria neste processo.

O presente artigo foi estruturado da seguinte forma: primeiramente foi feita uma revisão bibliográfica a cerca da temática resíduos eletrônicos, posteriormente é 
descrita a metodologia utilizada na pesquisa e, por fim, são apresentados os resultados e discussões e a conclusão.

\section{Resíduos Eletrônicos}

Os resíduos eletrônicos, resíduos eletroeletrônicos (REE) ou lixo eletrônico são os termos mais comuns utilizados para denominar todo e qualquer material eletro eletrônico descartado ou obsoleto (ELIXO, 2015). Atualmente, é o resíduo que mais cresce, dado o mercado acelerado de eletrônicos combinado à rapidez com que se tornam obsoletos (CELINSKI et al, 2013).

Resíduo eletrônico é definido por Favera (2008) como sendo todos os resíduos resultantes da rápida obsolescência de equipamentos eletrônicos. Nestes estão incluídos aparelhos compostos quase que totalmente por circuitos eletrônicos como televisores, celulares, computadores, impressoras, etc. Mas também estão incluídos equipamentos eletrodomésticos que possuem alguma parte eletroeletrônica. São exemplos: geladeiras, máquinas de lavar, batedeiras, etc.

A sociedade moderna vive produzindo novidades tecnológicas que motivam as pessoas a darem seus antigos aparelhos como desatualizados. O principal fator que pode motivar a desatualização destes equipamentos e a sua transformação em resíduo eletrônico é que, em geral, a aquisição de um a aparelho novo é monetária e tecnologicamente mais vantajosa que o reparo de um usado. Os impactos socioambientais associados ao rápido crescimento dos resíduos eletrônicos e sua consequente incapacidade de metabolização são considerados um risco para o meio ambiente e a saúde pública, devido aos crescentes volumes de sucatas geradas $\mathrm{e}$ as substâncias tóxicas presentes em sua composição (ROCHA et al, apud RIGOTTI, 2011).

Até pouco tempo atrás, os benefícios que o desenvolvimento tecnológico proporcionava como conforto, praticidade, comodidade, redução de horas de trabalho, diminuição de despesas, eram a justificativa para a realização de tantas inovações e aperfeiçoamento nessa área. Pouco se falava na degradação do meio ambiente e no risco de extinção de espécies da fauna e da flora, recursos hídricos e outros bens naturais. Nos dias atuais o panorama é outro. Governos, empresas e sociedade discutem amplamente os temas ligados aos resíduos sólidos e meio ambiente (FREITAS, 2010).

Os resíduos gerados pela rápida evolução dos equipamentos de informática e dos meios de comunicação, não se resume apenas aquele virtual que seriam os spams e as páginas que trazem informações conflitantes (lixo eletrônico intangível), existe também o resíduo físico que pode ser desde baterias, celulares e notebooks até grandes computadores e máquinas (lixo eletrônico tangível) que se tornam obsoletos com uma rapidez cada vez maior. Então pode se dizer que há dois tipos de lixo eletrônico: os tangíveis e os intangíveis (FREITAS, 2010).

Segundo Agência Brasileira de Desenvolvimento Industrial (ABDI, 2012) equipamentos eletroeletrônicos são todos aqueles produtos cujo funcionamento depende do uso de corrente elétrica ou de campos eletromagnéticos. Eles podem ser divididos em quatro categorias amplas: 


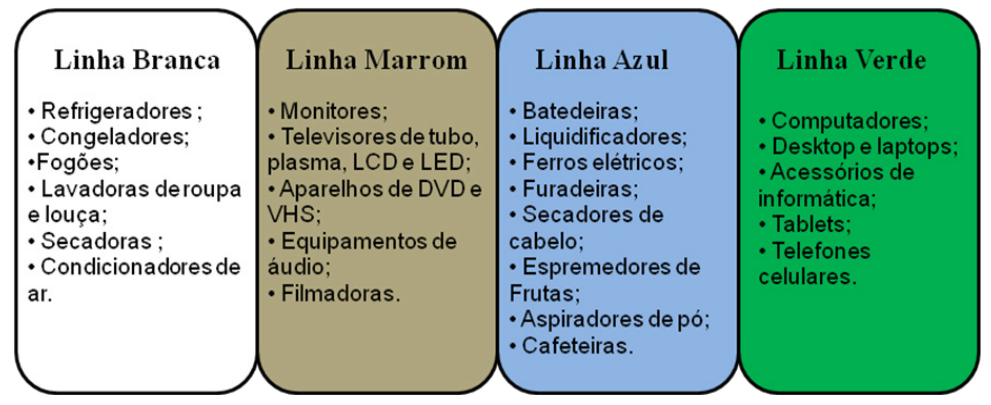

Figura 1 - Categorias dos Eletroeletrônicos (ABDI, 2012)

Ao fim de sua vida útil, esses produtos passam a ser considerados Resíduos de Equipamentos Eletroeletrônicos (REEE) e só chegam a esse ponto uma vez esgotadas todas as possibilidades de reparo, atualização ou reuso (ABDI, 2012).

Para Acosta, Padula e Wegner (2008), a rápida evolução tecnológica, com constantes inovações, novas versões, melhoras de rendimento e uso, faz com que os produtos de informática (computadores, impressoras, software e periféricos) tenham um ciclo de vida cada vez mais curto. Mesmo que a vida útil estimada de computadores seja de dez anos, na prática nos primeiros três ou quatro anos de utilização tornam-se obsoletos devido às exigências de novos programas ou novas versões dos sistemas operativos. Isso faz com que a vida útil deste tipo de produto seja extremamente curta, o que incentiva a aquisição de novas versões.

Continuamente, foram surgindo aparelhos eletrônicos aperfeiçoados e evoluídos. Ao propiciar comodidades ao homem, paralelamente, esse aparato tecnológico trouxe a obsolescência desses produtos, fato que incorreu o ato de "jogar no lixo" aquilo que estragava ou se tornava obsoleto e, atualmente, é cada vez mais frequente o descarte de eletroeletrônicos semi-novos, apenas para substituí-los por outro de tecnologia mais evoluída. Nesse contexto, toneladas de resíduos eletrônicos são descartados continuamente, provocando sérios impactos ao meio ambiente (PRUX, 2013).

Como conseqüência desse alto índice de inovação do setor, a cada ano se descarta milhões de produtos informáticos em todas as partes do mundo, para serem substituídos por novos modelos (CARROLL apud ACOSTA; PADULA; WEGNER, 2008). Essa gama de lançamentos sucessivos em velocidade cada vez mais rápida veio trazer obsolescência para uma enorme quantidade de produtos. Mudou-se o antigo costume de jogar no lixo apenas aquilo que estragava ou se tornava velho e, atualmente, é cada vez mais frequente as pessoas abandonarem produtos quase novos e ainda em bom estado, apenas pelo intuito de comprar outro com nova tecnologia considerada mais evoluída (PRUX, 2013).

Nesse contexto, toneladas de resíduos eletrônicos vêm sendo descartados continuamente, provocando grande impacto ambiental. São materiais de informática (computadores, impressoras, etc.), i-pods, celulares, televisores e toda uma quantidade enorme de material constituído por metais pesados e com alto grau de possibilidade de degradar a natureza quando inadequadamente tratados. Portanto, tem-se uma situação problemática que a sociedade brasileira precisa encontrar meios de equacionar, tal como já vem buscando de forma mais efetiva em relação a lâmpadas, pilhas e outros tipos de baterias (PRUX, 2013).

\subsection{Situação dos Resíduos Eletrônicos no Brasil}

O Brasil é o país emergente que produz o maior volume de resíduo eletroeletrônico por pessoa a cada ano. O alerta é da Organização das Nações Unidas (ONU), que lançou seu primeiro estudo sobre o tema. Segundo o estudo, o Brasil não tem estratégia para lidar com o fenômeno, que nem é tratado como prioridade pelas indústrias (RIBEIRO E SILVA apud ALMEIDA, 2015). 
Os resíduos eletrônicos devem constituir, no Brasil, motivo de grande preocupação por parte das autoridades governamentais e principalmente dos órgãos ambientais, seja devido às quantidades que vêm sendo gerados, e principalmente como resultado do elevado consumo e a rápida obsolescência de computadores e seus componentes nos últimos tempos (FREITAS, 2010).

Nunca os brasileiros renovaram com tanta rapidez os modelos de seus televisores, computadores, aparelhos de som e outros eletrônicos. Como consequência, surge um problema: ao adquirir um novo, o que fazer com o antigo? Enquanto o consumo aumenta, impulsionado pelo crescimento econômico, as políticas públicas para o descarte desse tipo de lixo não evoluem com a mesma intensidade (GOMES, 2011).

De acordo com o Site G1 (2015), a produção de lixo eletrônico no mundo todo alcançou quase 49 milhões de toneladas métricas, sete quilos por cada habitante do planeta, no ano de 2012. Para 2017 o número aumentará 33\%, é projetado o volume anual de 65,4 milhões de toneladas, segundo estudo publicado pela Universidade das Nações Unidas (UNU). Na América Latina, Brasil e México foram os países que geraram mais lixo eletrônico. O Brasil pôs no mercado em 2012 dois milhões de toneladas de eletrônicos e gerou 1,4 milhão de toneladas de resíduos eletrônicos, 7 quilos por habitante. Já o México lançou 1,5 milhão de toneladas de eletrônicos e gerou 1 milhão de toneladas de lixo, o equivalente a 9 quilos por habitante.

O descarte dos resíduos eletrônicos é de tamanha complexidade que diversos países criaram legislações próprias para o correto descarte e a minimização de danos à saúde e ao meio ambiente. No dia 05 de Agosto de 2010 foi aprovada, no Brasil, a Lei Federal $n^{\circ} 12.305$, sendo esta referente à Política Nacional de Resíduos Sólidos no Brasil, que obriga o destino adequado a esses resíduos. Na cidade de São Paulo, devido à elevada quantidade de lixo eletrônico, uma nova lei surgiu. A Lei Estadual 13.576 instituiu as normas para a reciclagem, gerenciamento e destino final dos lixos tecnológicos (ELIXO, 2015).
Um dos principais pontos da PNRS, principalmente ligado ao lixo eletrônico é a logística reversa, que nada mais é que um conjunto de ações para facilitar o retorno dos resíduos aos seus geradores para que sejam tratados e/ou reaproveitados em novos produtos (EDUARDO apud SILVA et al, 2013).

De acordo com Clock et al (apud ALMEIDA et al, 2015), o artigo 33 da Lei $\mathrm{n}^{\circ}$ 12.305/10 estabelece que “estão obrigados a estruturar e implementar sistemas de logística reversa, mediante retorno dos produtos após o uso pelo consumidor, de forma independente do serviço público de limpeza urbana e manejo dos resíduos sólidos, os fabricantes, importadores, distribuidores e comerciantes de produtos":

$$
\text { I - agrotóxicos, seus resíduos e embalagens, }
$$
assim como outros produtos cuja embalagem, após o uso, constitua resíduo perigoso, observadas as regras de gerenciamento de resíduos perigosos previstas em lei ou regulamento, em normas estabelecidas pelos órgãos do (Sistema Nacional do Meio Ambiente) Sisnama, do (Sistema Nacional de Vigilância Sanitária) SNVS e do (Sistema Unificado de Atenção à Sanidade Agropecuária) Suasa, ou em normas técnicas;

II - pilhas e baterias;

III - pneus;

IV - óleos lubrificantes, seus resíduos e embalagens;

V - lâmpadas fluorescentes, de vapor de sódio e mercúrio e de luz mista;

VI - produtos eletroeletrônicos e seus componentes.

Segundo Grimberg (apud ALMEIDA et al, 2015), a ausência de fiscalização da Lei Política Nacional de Resíduos Sólidos (PNRS) e de programas de educação ambiental nos municípios são importantes desafios que precisam ser enfrentados. A falta de legislação pertinente envolvendo incentivos às atividades de reciclagem neste segmento, a baixa conscientização da população em relação à sua importância, a complexidade e o alto custo da logística reversa, a pequena quantidade de pesquisas 
envolvendo o assunto e, também, certa acomodação governamental em relação aos resíduos eletrônicos tornam o problema de difícil solução.

A PNRS representa um marco para a sociedade brasileira no que toca à questão ambiental, com destaque para uma visão avançada na forma de tratar o lixo urbano. Traz uma concepção de vanguarda, ao priorizar e compartilhar, com todas as partes relacionadas ao ciclo de vida de um produto, a responsabilidade pela gestão integrada e pelo gerenciamento ambientalmente adequados dos resíduos sólidos. Dessa forma, o setor público, iniciativa privada e população ficam sujeitos à promoção do retorno dos produtos às indústrias após o consumo e obriga o poder público a realizar planos para o gerenciamento do lixo. A lei também consagra o viés social da reciclagem, com o estímulo à participação formal dos catadores organizados em cooperativas (ABDI, 2012).

\subsection{Consequências do descarte incorreto dos} resíduos eletrônicos

Destaca-se que algumas características dos resíduos eletrônicos impedem que eles sejam tratados em conjunto com os demais tipos de resíduos, visto que apresentam componentes não biodegradáveis, por isso não podem ser destinados a aterros sanitários. Esses resíduos são caracterizados por uma composição variada que abrange metais ferrosos, metais não ferrosos, vidro, plástico e outros materiais. O ferro e o aço são os materiais mais comumente encontrados em peso e correspondem a quase metade do peso total. Os plásticos são o segundo maior componente em peso, representando $21 \%$ dos resíduos eletrônicos. Metais não ferrosos, incluindo metais preciosos, representam 13\% do peso total dos equipamentos eletrônicos. (ONGONDO apud SILVA; PIMENTA; CAMPOS, 2013).

A problemática ambiental gerada pelo gerenciamento inadequado de resíduos em geral é de difícil solução. A maior parte das cidades brasileiras apresenta um serviço de coleta que não prevê a segregação dos resíduos, pois é comum ser observado hábitos de disposição final inadequados. Materiais sem utilidade amontoados indiscriminadamente e muitas vezes em locais indevidos como lotes baldios, margens de estradas, fundos de vale e margens de lagos e rios (MUCELIN E BELLINI apud SILVA, 2010).

Atualmente os problemas relacionados ao resíduo eletrônico constituem-se em mais um desafio a ser enfrentado pela sociedade. A quantidade de lixo cresce proporcionalmente à melhora da qualidade de vida do ser humano, o qual passa a adquirir bens de consumo em uma velocidade maior. Ao mesmo tempo em que isso ocorre, a oferta de novos produtos também se acelera, causando uma obsolescência cada vez mais rápida dos eletro-eletrônicos (CELINSKI et al, 2013).

Os eletrônicos descartados de forma incorreta representam o tipo de resíduo sólido de maior crescimento no mundo, mesmo em países em desenvolvimento. Um dos problemas dessa variação de resíduos está nas substâncias tóxicas não biodegradáveis em sua composição, isso aumenta a responsabilidade com sua destinação final (SILVA, 2010).

De acordo com Rigotti (2011) a tecnologia de informação, denominada como TI, tem um passivo ambiental grave. Haja vista que seus resíduos são jogados sem controle ao ambiente, o lixo eletrônico não só leva milhares de anos para decompor-se como também é um problema ambiental e de saúde pública por conta das substâncias tóxicas utilizadas em sua fabricação, como chumbo e mercúrio, que podem contaminar o solo, os lençóis freáticos e causar doenças como o câncer.

Os resíduos eletrônicos quando descartados de modo incorreto podem gerar sérios riscos ao meio ambiente. Este fator se dá devido ao uso de metais pesados altamente tóxicos na composição destes equipamentos. Dentre estes metais, os mais comumente encontrados são o mercúrio, berílio e chumbo. Quando o descarte incorreto ocorre, tais materiais são enterrados junto dos equipamentos, sendo então absorvidos pelos solos com os quais tiveram contato, contaminando, 
posteriormente, os lençóis freáticos. Outro método incorreto (e comumente feito) é o da queimada dos materiais, liberando toxinas extremamente perigosas no ar. Além destes fatores expostos, ainda encontra-se em risco o trabalhador responsável pelo descarte irregular, visto seu contato direto com tais fumaças tóxicas ou até mesmo pelo consumo de água próximo a regiões de descarte (quando enterrados), podendo causar graves danos à saúde. Assim, o descarte correto é de extrema importância não só para o meio ambiente, mas também para a saúde humana (E-LIXO, 2015).

Equipamentos eletrônicos como computadores, impressoras, scanners, câmeras, celulares, rádios, televisores, aparelhos de som, aparelhos elétricos, lâmpadas eletrônicas, dentre outros, contém inúmeros elementos poluentes responsáveis pela contaminação do solo, causando prejuízos a agricultura e aos lençóis subterrâneos de água. Isso pode ocasionar a contaminação da natureza, este lixo eletrônico acaba afetando a população local que vive e extrai recursos do meio contaminado. (GALDINO E QUEIROZ, 2011).

\subsection{Soluções adequadas}

O que fazer com os resíduos eletrônicos? Prux (2013) diz que a resposta para esta questão parte de dois pressupostos:

a) o primeiro deles, é que segundo o Código de Proteção e Defesa do Consumidor, o Poder Público deve ter participação ativa no mercado de consumo e, neste ponto, se enquadram as políticas destinadas para a correta destinação do resíduo eletrônico. E elas acontecem quando existem formas organizadas para coleta, empresas que transportem adequadamente o material e outras que o reaproveitem, reciclem ou o tratem, bem como, locais adequados para depósito do que sobrar;

b) em segundo lugar, o fornecedor deve ser responsável pelos processos de fornecimento em toda sua trajetória, da coleta de insumos, passando pela fabricação, comercialização, chegando até o uso e posteriormente o seu descarte. Cabe aos fornecedores o papel de atores principais no sentido providenciarem meios para solução dos problemas de poluição ambiental gerados pelo resíduo eletrônico advindo de sua atividade de fornecimento. Ou seja, aquele que coloca o produto no mercado compete a obrigação de ter iniciativas para que esse tipo de lixo seja recolhido sem causar danos ambientais, pois quando tal acontece junto com a deterioração do meio ambiente vem o prejuízo à saúde da população.

Partindo desses pressupostos, as possíveis soluções para o gerenciamento adequado dos resíduos eletrônicos estão relacionadas com a prática da logística reversa pelas empresas fabricantes de equipamentos eletrônicos, reaproveitamento e reciclagem.

\subsubsection{Logística reversa}

A logística reversa compreende o gerenciamento do fluxo inverso dos produtos, após o consumo, abrangendo os processos de coleta, transporte, armazenagem, estoque e desmontagem, vai desde o ponto de consumo até o ponto de origem, e tem o objetivo de agregar valor aos resíduos e minimizar os impactos causados ao meio ambiente. (ROGERS E TIBBENLEMBK apud SILVA; PIMENTA; CAMPOS, 2013).

A logística reversa é um termo utilizado frequentemente para se referir ao papel da logística no retorno de produtos, redução de fornecimentos, reciclagem, substituição e reutilização de materiais, eliminação de desperdícios, reprocessamento, reparação e refabricação (CLOCK et al, apud ALMEIDA, 2015).

Para Leite (apud ACOSTA; PADULA; WEGNER, 2008) a logística reversa é uma área da logística empresarial que planeja, opera e controla o fluxo e as informações logísticas correspondentes, do retorno dos bens de pós-venda e de pós-consumo, ao ciclo de negócio ou ao ciclo produtivo, por meio dos canais de distribuição reversos, agregando-lhes valor de diversas naturezas: econômico, ecológico, legal, logístico, de imagem corporativa, entre outros. 
A PNRS aponta a logística reversa como uma alternativa de se assumir a responsabilidade compartilhada do ciclo de vida de produtos, promovendo o retorno dos produtos, após o uso pelo consumidor (SILVA; PIMENTA; CAMPOS; 2013).

Conforme definição apresentada na própria legislação, a logística reversa é um instrumento de desenvolvimento econômico e social caracterizado por um conjunto de ações, procedimentos e meios destinados a viabilizar a coleta e a restituição dos resíduos sólidos ao setor empresarial, para reaproveitamento, em seu ciclo ou em outros ciclos produtivos, ou outra destinação final ambientalmente adequada. É através desse sistema, por exemplo, que materiais recicláveis de um produto eletrônico em fim de vida útil descartado pelo consumidor poderão retornar ao setor produtivo na forma de matéria-prima (ABDI, 2012).

A logística reversa é um processo de planejamento, implementação e controle da eficiência e custo efetivo do fluxo de matérias-primas, produtos em processo e produtos prontos e informações relacionadas ao produto, do ponto de consumo para o ponto de origem do produto, com a finalidade de recuperar o valor ou destinar à apropriada disposição, com um enfoque ambientalmente correto. No setor de fabricação e comercialização de produtos informáticos os sistemas de logística reversa são implementados cada vez mais com a finalidade de reaproveitar os produtos depois do fim de vida útil, como uma via rentável de redução de custos, maximizando o uso de matérias-primas que impactam diretamente na redução de lixo informático (ACOSTA; PADULA; WEGNER; 2008).

O papel do consumidor nesse processo é o de efetuar a devolução de seus produtos e embalagens aos comerciantes ou distribuidores após o uso. Aos comerciantes e distribuidores compete efetuar a devolução aos fabricantes ou aos importadores dos produtos e embalagens reunidos ou devolvidos. Por sua vez, os fabricantes e os importadores deverão dar destinação ambientalmente adequada aos produtos e às embalagens reunidos ou devolvidos, sendo o rejeito encaminhado para a disposição final ambientalmente adequada, na forma estabelecida pelo órgão competente do SISNAMA e, se houver, pelo plano municipal de gestão integrada de resíduos sólidos (ABDI, 2012).

O grande desafio da logística reversa reside no custo associado à operacionalização do sistema em um país de extensão continental e com suas particulares complexidades logísticas. É sabido que qualquer sistema que seja estabelecido incorrerá em maiores dispêndios, ora tratados como custos quando apreciados sob a ótica puramente econômica, ora encarados com investimento necessário para um mundo sustentável. Um olhar mais atento e consciente a essa questão indica que o aparente aumento de custo não configura de fato um aumento, mas sim a antecipação de custos que incorreriam no futuro para remediar o impacto negativo ao meio-ambiente causado pelo descarte inadequado de resíduos (ABDI, 2012).

\subsubsection{Reciclagem}

Para Sant'Anna (2012), a busca para soluções para reprocessar matérias, componentes e equipamentos jogados no lixo para que eles se tornem úteis novamente e possa ser reinseridos no mercado chame-se reciclagem.

A reciclagem pode ser considerada a alternativa mais viável para os resíduos eletrônicos. A reciclagem consiste em separar os materiais que compõe um objeto e prepará-los para serem usados novamente como matéria prima dentro do processo industrial. Nem sempre a reciclagem se destina à reinserção dentro do mesmo ciclo produtivo: um computador reciclado pode gerar materiais que vão ser utilizados em outras indústrias. (FERREIRA et al, apud RIGOTTI, 2011).

Os descartes dos equipamentos eletroeletrônicos considerados inadequados ao uso ou sucateados, na maioria das vezes não recebem o tratamento adequado, sendo que alguns, dependendo do estado de conservação, poderiam ser reaproveitados, através de um processo de reciclagem, devendo as empresas fabricantes estar 
propensas a receberem esse lixo para reaproveitarem parte em outros equipamentos novos ou efetuarem campanhas de recuperação dessas máquinas para posterior doação (FERREIRA et al 2008).

$\mathrm{O}$ processo de gerenciamento de resíduos e reciclagem é extremamente complexo e depende de mão de obra especializada. O processo inicia-se logo após a coleta do material por pessoal especializado e devidamente treinado. Utilizando roupas de proteção, os funcionários iniciarão o processo de manufatura reversa, ou seja, as peças serão desmontadas. Seus componentes classificados (tais como vidros, plásticos, metais, metais pesados, elementos químicos). Após a classificação, as substâncias tóxicas (nocivas ao meio ambiente e à saúde humana) serão neutralizadas com o uso de diversos processos físico-químicos, impedindo que os mesmos possam gerar qualquer tipo de risco (E-LIXO, 2015).

Os processos de reciclagem destinam-se a reaproveitar os resíduos como matéria prima para elaboração de um novo produto, e assim reintroduzi-lo na cadeia produtiva. Estes processos minimizam o uso de recursos naturais e diminuem a quantidade de lixo a ser descartados. A reciclagem dos resíduos eletrônicos requer uma maior atenção, já que os equipamentos são compostos por materiais que podem contaminar o meio ambiente e fazer mal à saúde (SANT’ANA; 2012).

A indústria da reciclagem não é parte considerada na PNRS como corresponsável pela gestão dos resíduos sólidos, mas é parte imprescindível para efetividade dos objetivos da lei. Valorização e incentivo da utilização de matérias primas recicladas dentro da etapa de manufatura é base para fortalecimento da indústria da reciclagem (ABDI, 2012).

\subsubsection{Reaproveitamento}

Para Silva et al (2013) o reaproveitamento se dá de duas maneiras: reforma dos equipamentos que se encontram em melhores condições (para serem emprestados ou doados a entidades sociais), e desmonte dos demais, que terão suas peças utilizadas em outros equipamentos, ou ainda encaminhadas para recicladores .
A reutilização nada mais é que o reaproveitamento de materiais e produtos que não mais estão em uso. Seja com outra função ou mesmo por outra pessoa. Com relação à informática, considerando que muitos dos componentes eletrônicos utilizados na fabricação dos computadores são nocivos ao meio ambiente, à reutilização e o reaproveitamento de placas e circuitos fazem-se extremamente necessários. Juntandose a reutilização das peças e dos circuitos, a doação é um caminho bastante eficaz e politicamente correto, tema bastante discutido nos dias de hoje, recebendo o nome de responsabilidade social (PINTO apud RIGOTTI, 2011).

Com o reaproveitamento dos resíduos eletrônicos, muitas entidades sociais, creches e programas sociais em geral têm a possibilidade de promover a inclusão digital capacitando mão de obra, proporcionar o primeiro contato com a tecnologia e acima de tudo evitar que boa parte do lixo venha a ser descartado de forma inadequada. Outra forma de uso desse material é o artesanato (SILVA et al, 2013).

\section{Materiais e métodos}

O principal objetivo deste trabalho é caracterizar os procedimentos utilizados no gerenciamento dos resíduos eletrônicos na organização militar $13^{\mathrm{a}}$ Companhia Comunicações Mecanizada da cidade de São Gabriel/RS, expondo e levantando possíveis problemas neste processo.

Para que o objetivo geral fosse alcançado foi realizado um estudo de caso, sendo que os dados foram coletados por meio de observação direta, entrevistas semi-estruturadas com os responsáveis pela gestão ambiental e tecnologia da informação da organização militar e aplicação de questionário. Para Lakatos e Marconi (2003), questionário é um instrumento de coleta de dados e é constituído por uma série de perguntas, que devem ser respondidas por escrito e sem a presença do entrevistador. O questionário aplicado foi estruturado 
com perguntas fechadas/simples, semi-abertas, de múltipla escolha e com matriz de resposta (Anexo 1). Para determinar as perguntas do questionário, levaram-se em consideração os objetivos do presente trabalho.

Quantos aos procedimentos inicialmente foi desenvolvida uma pesquisa bibliográfica, que, de acordo com Leal e Souza (2006), é aquela elaborada a partir de material já publicado, constituído principalmente de livros, artigos periódicos e material disponibilizado na internet. Consiste em apresentar e comentar o que outros autores escreveram sobre o tema, enfatizando as diferenças ou semelhanças que existem entre os conceitos.

Quanto aos objetivos foi uma pesquisa exploratória, como afirmam Leal e Souza (2006) visa proporcionar maior familiaridade com o problema objetivando torná-lo explícito ou construir hipóteses. Envolve levantamento bibliográfico, entrevistas com pessoas que tiveram experiências práticas com o problema pesquisado, análise de exemplos que estimulem a compreensão.

\section{Resultados e discussões}

Esta parte do artigo apresenta inicialmente o histórico da organização militar e como é feita a gestão dos resíduos eletrônicos na unidade militar $13^{\mathrm{a}}$ Companhia de Comunicações Mecanizada. Após, será descrito o processo utilizado para o descarte do resíduo eletrônico, desde o momento em que é detectada a inutilidade do equipamento até seu destino final. Por fim, será feita uma descrição do método de descarte utilizado.

\subsection{Histórico da $13^{\mathrm{a}}$ Companhia de Comunicações Mecanizada}

O marco inicial de implantação da $13^{\mathrm{a}}$ Companhia de Comunicações Mecanizada (13 ${ }^{\text {a }}$ Cia Com Mec) no município de São Gabriel RS foi o dia 19 de março de 1843, em plena Revolução Farroupilha, quando o General Luís Alves de Lima e Silva, então Barão de Caxias, ocupou São Gabriel. Logo à sua chegada, providenciou a criação de uma base de apoio na cidade, com o efetivo de um Batalhão de Caçadores sob o comando do Coronel Manuel Marques de Souza e ordenou ao Major Miguel de Frias Vasconcellos que levantasse o Mapa Topográfico da Vila de São Gabriel, inclusive a planta do forte, que teve sua construção iniciada no mesmo período. O forte, que tomou o seu nome, era de forma irregular composto de um pavilhão de pedra, de duas muralhas sobrepostas e dois canhões La Hytte de quatro polegadas, no local conhecido, desde então, como "Forte Caxias". Em 1857, o Forte foi reformado e ampliado. No ano de 1880 , foi totalmente demolido e, sobre seus escombros, surgiu o quartel de forma quadrilátera que, embora sofresse algumas reformas, é o mesmo que hoje abriga a $13^{\mathrm{a}}$ Companhia de Comunicações Mecanizada, passando este novo aquartelamento a ser conhecido como "Praça Forte de Caxias" (VIEIRA, 2014).

Em 08 de junho de 1999, por intermédio da Portaria $\mathrm{n}^{\circ} .311$ do Ministério da Defesa, da mesma data, a $13^{\text {a }}$ Companhia de Comunicações recebeu a denominação histórica de "Companhia Praça Forte de Caxias" num reconhecimento do Exército à importância e influência do histórico local e também, como mais uma forma de homenagear o Duque de Caxias, Patrono do Exército Brasileiro (VIEIRA, 2014).

Missão - A fim de contribuir com o escalão superior na defesa da pátria, instalar, explorar e manter o Sistema de Comunicações da $3^{\text {a }}$ Brigada de Cavalaria Mecanizada nas operações de defesa externa, nas operações de garantia da lei e da ordem e nas ações subsidiárias. A fim de cooperar com a Comunidade Local, contribuir com o desenvolvimento nacional na área em que está inserida com responsabilidade social (SITE 13ª CIA COM MEC, 2015).

Visão de futuro - Ser reconhecida no âmbito da $3^{\mathrm{a}} \mathrm{Bda} \mathrm{C}$ Mec como OM que, otimizando processos, gera eficiência no cumprimento de sua atividade fim, zela pelo seu patrimônio e age com responsabilidade social, com relação ao público interno e à comunidade em que está 
inserida, com ênfase no bem estar da família militar (SITE 13 CIA COM MEC, 2015).

\subsection{O gerenciamento dos resíduos eletrônicos na $13^{\mathrm{a}}$ Companhia de Comunicações Mecanizada}

$\mathrm{Na}$ unidade militar $13^{\mathrm{a}}$ CIA COM MEC, o descarte dos resíduos eletrônicos é administrado pelos responsáveis das áreas de TI (Tecnologia da Informação) e gestão ambiental.

De acordo com os entrevistados a $13^{\text {a }}$ CIA COM MEC está preocupada com o descarte correto dos resíduos eletrônicos devido ao fato da quantidade de equipamentos obsoletos serem cada vez maior em um curto espaço de tempo e, devido a isso, possui um sistema de gerenciamento destes resíduos.

Quando perguntado quais equipamentos eletrônicos tornam-se obsoletos ou inservíveis com maior freqüência estes responderam que são impressoras, CPUs, monitores e notebooks.

Considerando que a vida útil de um computador é de mais ou menos 4 anos, quando questionados sobre o que é feito com os computadores inservíveis estes responderam que durante vários anos estes equipamentos eram depositados em um local junto a seção de informática da organização militar. No ano de 2014, foi realizado o descarte de um lote de equipamentos eletrônico junto à empresa Químea Soluções na cidade de Santa Maria RS. Neste ano foi feito contato com a Prefeitura Municipal de São Gabriel-RS onde esta indicou o depósito deste material no antigo Engenho São Jorge, onde uma empresa contratada pela própria prefeitura realizará a apanha e a destinação correta deste material. Porém, quando os computadores que ainda funcionam, no entanto deixaram de atender as necessidades tecnológicas exigidas, estes são encaminhados para doação.

Segundo os entrevistados existe um depósito onde são armazenados os eletrônicos obsoletos e inservíveis, como mostram as fotos a seguir:
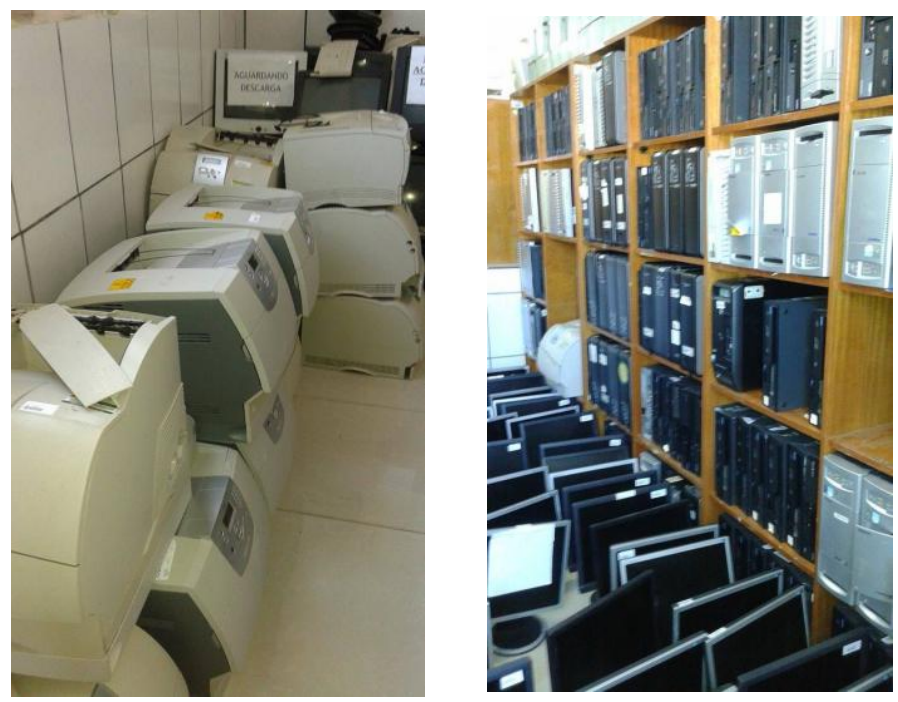

Figura 2 - Impressoras e CPUs em desuso Fonte: Dados da pesquisa 

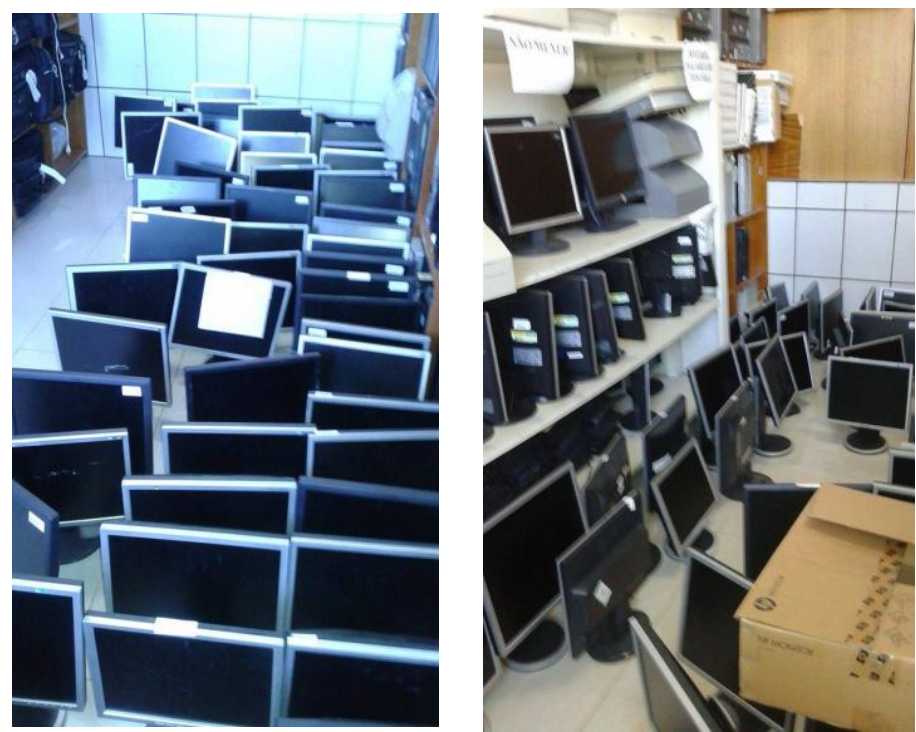

Figura 3 - Monitores em desuso

Fonte da pesquisa

Quando questionados como é feito o gerenciamento do descarte dos resíduos eletrônicos, foi explicado que este procedimento foi planejado e executado através do Plano de Gestão Ambiental da organização militar no ano de 2014 e atualizado neste ano, onde consta o local para depósito destes materiais, destacando que este local tenha que ser de piso de cimento e revestido com uma lâmina emborrachada, com cobertura em boas condições para não existir infiltrações ou goteiras e os materiais eletrônicos depositados devem estar fechados ou embalados para que não fiquem expostos as intempéries do tempo, impedindo assim reações químicas provocadas pelo ar ou umidade. Sendo que os materiais depositados, na medida do possível, não devem permanecer mais de 90 dias armazenados neste local. Após a concentração de um lote este será descartado na empresa contratada pela prefeitura onde será investigada a idoneidade desta, como descartes anteriores, credenciamento junto ao IBAMA, local de depósito e desmembramento de componentes, cadastro no SICAF (sistema de cadastro de fornecedores) e no SIAFI (sistema de administração financeira) verificado assim o destino correto do lixo eletrônico desta organização.

De acordo com os entrevistados, o lixo eletrônico é encaminhado para empresas que recolhem este tipo de material, no ano de 2014 foi feito o descarte através da empresa Químea Soluções e neste ano foi encaminhado para um depósito cedido pela Prefeitura Municipal que se responsabiliza pelo descarte final destes materiais. Quanto ao número de vezes que é feito o descarte, foi respondido que durante o período de 12 meses os resíduos eletrônicos são encaminhados para o descarte de uma a duas vezes (depende da quantidade). A estimativa da quantidade de lixo eletrônico descartado foi de $80 \mathrm{~kg}$ no primeiro descarte, sendo que no próximo descarte a estimativa é de mais ou menos $120 \mathrm{~kg}$.

Segundo dados da pesquisa, o quadro a seguir mostra com que freqüência são descartados os seguintes aparelhos eletrônicos:

\begin{tabular}{|c|c|c|c|c|l|}
\hline & $\begin{array}{c}\text { A cada 6 } \\
\text { meses }\end{array}$ & $\begin{array}{c}\text { Umavez } \\
\text { porano }\end{array}$ & $\begin{array}{c}\text { A cada 2 } \\
\text { anos }\end{array}$ & $\begin{array}{c}\text { A cada 5 } \\
\text { anos }\end{array}$ & $\begin{array}{c}\text { Não costuma } \\
\text { ser } \\
\text { descartado }\end{array}$ \\
\hline Monitor & & $\mathrm{x}$ & & & \\
\hline CPU & & $\mathrm{x}$ & & & \\
\hline Impressora & & & & $\mathrm{x}$ & \\
\hline Copiadora & & & & & $\mathrm{x}$ \\
\hline Roteador & & & & & $\mathrm{x}$ \\
\hline Estabilizador & & & & & $\mathrm{x}$ \\
\hline Telefone fixo & & & & & $\mathrm{x}$ \\
\hline TV & & & & & $\mathrm{x}$ \\
\hline DVD & & & & $\mathrm{x}$ & \\
\hline \begin{tabular}{c} 
Notebook \\
\hline $\begin{array}{c}\text { Teclado e } \\
\text { mouse }\end{array}$
\end{tabular} & & $\mathrm{x}$ & & & \\
\hline
\end{tabular}


Sobre as principais dificuldades encontradas pela $13^{\mathrm{a}}$ CIA COM MEC na gestão dos resíduos eletrônicos foram citados: falta de empresas fornecedoras que pratiquem a logística reversa; local adequado para destinação destes resíduos na cidade de São Gabriel-RS e inexistência de políticas públicas que obriguem as empresas a realizarem a logística reversa.

\section{Conclusões}

O principal objetivo deste artigo foi caracterizar os procedimentos utilizados no gerenciamento dos resíduos eletrônicos na organização militar $13^{\mathrm{a}}$ Companhia de Comunicações Mecanizada, expondo e levantando possíveis problemas neste processo. Através da presente pesquisa pôde-se concluir que a organização militar está dando um destino final adequado aos resíduos eletrônicos gerados na organização.

Os resíduos eletrônicos são os equipamentos que se tornaram obsoletos ou deixaram de funcionar e o número cada vez mais elevado destes resíduos faz com que tanto empresas, quanto população e governo tenham uma preocupação com sua destinação final. Por possuírem materiais tóxicos as consequências do descarte incorreto pode acarretar danos ao meio ambiente e consequentemente à saúde das pessoas, pois se essas toxinas são absorvidas pelo solo com os quais tiveram contato podem contaminar os lençóis freáticos ou se forem queimadas produzirem fumaças tóxicas, o que poderá interferir na saúde da população.

A partir dessa premissa, a $13^{\text {a }}$ Companhia de Comunicações Mecanizada adotou um Plano de Gerenciamento Ambiental que visa minimizar os impactos negativos causados ao meio ambiente no que diz respeito ao descarte inadequado dos resíduos eletrônicos. Sendo assim, é possível constatar que, apesar do número elevado de equipamentos eletrônicos obsoletos e inservíveis, mais especificamente computadores e seus periféricos, o armazenamento e destinação final são adequados a uma gestão ambiental de qualidade.

O gerenciamento dos resíduos é feito da seguinte forma: armazenagem em depósito específico até que haja um número determinado de equipamentos que possam ser encaminhados para descarte, sendo que no ano de 2014 foi contratada uma empresa para recolher tais resíduos e em 2015 foram encaminhados para o depósito cedido pela prefeitura municipal o qual se responsabiliza por contratar uma empresa para fazer o recolhimento e dar a destinação final. Tais empresas são especializadas no recebimento/recolhimento, descaracterização e posterior envio dos resíduos a usinas ou empresas específicas cuja finalidade é reciclar os itens recolhidos ou enviados.

Considerando o resultado da pesquisa, propõe-se que, primeiramente, a organização militar faça $o$ acompanhamento da destinação final realizada pela prefeitura para que se tenha a certeza de que os resíduos eletrônicos serão armazenados e encaminhados de forma adequada e, posteriormente, que seja feita uma análise da viabilidade de contratar novamente uma empresa sem ter que encaminhar os resíduos para terceiros, visto que, assim, haverá um maior controle da destinação final dos resíduos eletrônicos. Além disso, como melhoria no processo de gerenciamento dos resíduos e para reduzir o número de equipamentos obsoletos, a organização militar poderia: comprar equipamentos eletrônicos somente de empresas que pratiquem a logística reversa; fazer doações a ONGs ou entidades assistenciais dos equipamentos que funcionam, mas que deixaram de atender a necessidade tecnológica exigida; e encaminhar para empresas que possam utilizar e reciclar as peças que ainda funcionam (no conserto ou fabricação) de equipamentos e, assim, colocar novamente parte destes resíduos na cadeia produtiva.

No decorrer da pesquisa, algumas limitações foram encontradas, entre elas destaca-se a dificuldade de encontrar bibliografia disponível, principalmente livros que tratassem da temática "resíduos eletrônicos" e os artigos científicos encontrados, na grande maioria, 
possuíam conceitos e idéias muito semelhantes e, devido a isso, não foi possível fazer uma análise mais completa do tema.

Através da análise deste trabalho, pode-se sugerir a realização de pesquisas relacionadas ao estudo da viabilidade das formas com que é feito o descarte dos resíduos eletrônicos pela organização militar $13^{\mathrm{a}}$ Companhia de Comunicações Mecanizada, onde poderá ser feito uma comparação dos procedimentos utilizados.

\section{Agradecimentos}

Agradecimentos a revisores, colaboradores e agências de fomento.

\section{Referências}

$$
\text { E-Lixo. Disponível }
$$
em: $<$ http://www.elixo.org.br/reciclagem-lixoeletronico/> Acesso em: 24/jun/2015.

$13^{\mathrm{a}}$ CIA COM MEC. Disponível em: < www.13ciacommec.eb.mil.br/index.php/component/ content/?view...> Acesso em: 10/jun/2015.

ABDI, Agência Brasileira de Desenvolvimento Industrial. Logística reversa de equipamentos eletroeletrônicos: análise da viabilidade técnica e econômica. 2012. Disponível em: http://www.abdi.com.br/Estudo/Logistica\%20revers a\%20de\%20residuos_pdf $>$ Acesso em: $13 /$ jun/2015.

ACOSTA, Byron; PADULA, Antonio Domingos; WEGNER, Douglas. Logística Reversa

como Mecanismo para Redução do Impacto Ambiental Originado pelo Lixo Informático. Revista Eletrônica de Ciências Administrativas, v. 7, n.1, p. 1-12, maio 2008.

ALMEIDA, Mislene Aparecida; PAPANDREA, Pedro José; CARNEVALI, Marcos; ANDRADE, Aurélio Xavier de;

CORREA, Francisco de Paulo Victor; ANDRADE, Maria Rita Martins. Destinação do lixo eletrônico: impactos ambientais causados pelos resíduos tecnológicos. E-locução Revista Científica da FAEX. Ed 7. Ano 4. 2015.

CELINSKI, Tatiana Montes; CELINSKI, Victor George; REZENDE, Henrique Ghizzi; FERREIRA, Juliana Stavasz. Perspectivas para reuso e reciclagem do lixo eletrônico. 2011. Disponível em: < http://www.ibeas.org.br/congresso/Trabalhos2011/II I-020.pdf $>$ Acesso em: 18/jun/2015.

CELINKI, Tatiana Montes; CERUTTI, Diolete Marcante Lati; IELO, Frederico Guilherme de Paula Ferreira;

CELINSKI, Victor George; CERUTTI, Idomar Augusto. Gestão do lixo eletrônico: desafios e oportunidades. 2013. Disponível em: < http://www.ibeas.org.br/congresso/Trabalhos2013/I015.pdf $>$ Acesso em: 03/ago/2015.

FAVERA, Eduardo Ceretta Dalla. Lixo eletrônico e a sociedade. 2008. Disponível em: <http://wwwusr.inf.ufsm.br/ favera/elc1020/t1/artigoelc1020.pdf > Acesso em: 07/abr/2015.

FERREIRA, Juliana Martins Bessa; FERREIRA, Cláudio Antonio. A Sociedade de Informação e o Desafio da Sucata Eletrônica. Revista de Ciências Exatas e Tecnologia. São Paulo, v. III n. 3 p. 157-169, dez 2008. Disponível na internet http://sare.unianhanguera.edu.br/index.php/rcext/arti cle/viewFile/417/413. Acesso em 17/mai/2015.

FREITAS, Débora Maria da Silva. Diagnóstico proposto de modelo de gestão dos resíduos eletroeletrônicos gerados nos ministérios do governo brasileiro. 2010 . Disponível em: $<$ http:file://D:/bkp\%20user/Desktop/Lixo\%20eletr $\% \mathrm{C} 3 \%$ B4nico/Untitled\%20Document.html $>$ Acesso em: $11 /$ jul/2015.

G1. Em 2017, volume de lixo eletrônico no mundo aumentará 33\%, alerta estudo. Disponível em:

$<$ http://g1.globo.com/tecnologia/noticia/2013/12/em2017-volume-de-lixo-eletronico-no-mundoaumentara-33-alerta-estudo.html $>$ Acesso em 17/mai/2015.

GOMES, Luciani. O que fazer com o nosso lixo eletrônico. 2011. Disponível em: < http://www.istoe.com.br/reportagens/156841_O+Q $\mathrm{UE}+\mathrm{FAZER}+\mathrm{COM}+\mathrm{O}+\mathrm{NOSSO}+\mathrm{LIXO}+\mathrm{ELETRON}$ ICO $>$ Acesso em 30/mar/2015. 
GALDINO, Jean Carlos da Silva; QUEIROZ, Maria Jane de. E-lixo: o problema e a solução ao crescente consumo e descarte de produtos eletrônicos. 2011. Disponível em:

http://www3.ifrn.edu.br/ jeangaldino/dokuwiki/lib/ exe/fetch.php?media=artigo_lixo_eletronico_jean_j ane_i_senacem.pdf $>$ Acesso em:10/mar/2015.

LEAL, Alzira Elaine Melo; SOUZA, Carlos Eduardo Gerzson de. Construindo o conhecimento pela pesquisa: orientação básica para elaboração de trabalhos científicos. Santa Maria: Sociedade Vicente Pallotti, 2006.

LAKATOS, Eva Maria; MARCONI, Marina de Andrade. Fundamentos de Metodologia Científica. 5.ed. São Paulo: Atlas, 2003.

NATUME, Rosane Yoshida; ORÉFICE, Eduardo Henrique; TRENTINI, Alice Bianchi; OLIVEIRA, Taiane Vasconcelos de. Gerenciamento de resíduos de informática nas universidades federais do Brasil. 2011. Disponível em: < https://repositorio.ufsc.br/bitstream/handle/1234567 89/32844/7.25.pdf> Acesso em: 10/mar/2015.

PRUX, Oscar Ivan. A responsabilidade pelo reaproveitamento, reciclagem ou descarte do lixo eletrônico. 2013. Disponível em: < http://www.parana-online.com.br/colunistas/direitoconsumidor/67059/A+RESPONSABILIDADE+PE LO+REAPROVEITAMENTO+RECICLAGEM+O U+DESCARTE+DO+LIXO+ELETRONICO $>$ Acesso em: 02/ago/2015.

RIGOTTI, Cláudia Michele. Gestão do lixo eletrônico nos municípios de abrangência das SDR do extremo Oeste de Santa Catarina. 2011. Disponível em: < http://www.uniedu.sed.sc.gov.br/wpcontent/uploads/2013/10/Claudia-MicheleRigotti.pdf $>$ Acesso em: 02/mai/2015.

SANT'ANNA, Gerson da Silva. Reciclagem do lixo eletrônico. 2012. Disponível em: < http://www.avm.edu.br/docpdf/monografias_publica das/K219276.pdf> Acesso em: 13/jun/2015.

SILVA, Agnaldo Francisco da; LIMA, Cristina Maria Valadares de; SANTOS, Jordano Henrique dos;
SILVA, Paulo Victor Salviano da; SILVA, Rafael Fávero. Lixo eletrônico: como dar uma melhor destinação. 2013. Disponível em: $<$ http://www.feol.com.br/revista/index.php/R1/articl e/view/31/56> Acesso em: 01/mai/2015.

SILVA, Arivano; NUNES, Eliangella; ARAÚJO, Eziu; GUIMARÃES, Gilberto; CASTRO, Ronald. Lixo eletrônico e o impacto ambiental. 2010. Disponível em:

http://www.administradores.com.br/_resources/files/ _modules/academics/academics_3022_2010052319 3948e19d.pdf> Acesso em: 24/mai/2015.

SILVA, Lorena Albuquerque Adriano da; PIMENTA, Handson Cláudio Dias; CAMPOS, Lucila Maria de Souza. Logística reversa dos resíduos eletrônicos do setor de informática: realidade, perspectivas e desafios da cidade do Natal-RN. Revista Produção on line. Florianópolis-SC. V 13. n 2. 2013.

SELPIS, Adriano Nicolau; CASTILHOS, Renata de Oliveira; ARAÚJO, João Alberto Borges de. Logística reversa de resíduos eletroeletrônicos. 2011. Disponível em: < http://webresol.org/textos/121-387-1-pb.pdf $>$ Acesso em: 24/mai/2015.

SILVA, Janari Rui Negreiros. Lixo eletrônico: um estudo de responsabilidade ambiental no contexto do instituto de educação ciência e tecnologia do Amazonas - IFAM campus Manaus centro. 2010. Disponível em: < http://www.ibeas.org.br/congresso/Trabalhos2010/II I-009.pdf> Acesso em: 02/mai/2015.

SHONS, Paula Cristina. O gerenciamento dos resíduos eletroeletrônicos: um estudo sobre as empresas de informática em São Miguel do Oeste. 2012. Disponível em: < http://revista.ctai.senai.br/index.php/edicao01/article /view/277/241> Acesso em: 05/mai/2015.

VIEIRA, Licielo Romero. Eficiência ambiental e melhoria econômica a partir da gestão ambiental em órgãos públicos: o caso da $13^{\mathrm{a}}$ Companhia de Comunicações Mecanizada em São Gabriel-RS. São Gabriel. 2014. 


\section{Anexo 1}

\section{QUESTIONÁRIO}

Prezado(a) Senhor(a)

Estou desenvolvendo meu Trabalho de Conclusão do Curso de Especialização em Gestão Pública e Meio Ambiente e conto com o seu apoio para o desenvolvimento da pesquisa de campo, através do preenchimento do questionário abaixo. O objetivo principal do trabalho é identificar como é feito o descarte de resíduos eletrônicos pela unidade militar 13ํㅡㄹ Companhia de Comunicações Mecanizada.

Antecipadamente, agradeço a sua colaboração.

1) Quais equipamentos eletrônicos tornam-se obsoletos ou inservíveis com maior frequência:
( ) Monitores
( ) CPU
( ) Teclado e mouse
( ) Estabilizador
( ) Impressora
( ) Copiadora
( ) Caixas de som
( ) Notebooks
( ) Telefone fixo
( ) Roteador
( ) TV
( ) DVD
( ) Outros. Quais?

2) A vida útil de um computador é de mais ou menos 4 anos. O que é feito com os computadores inservíveis?

3) Quanto aos computadores que funcionam, porém deixaram de atender as necessidades tecnológicas exigidas, estes são:

( ) encaminhados para doação

( ) reciclados

( ) descartado juntamente com os demais lixos tecnológicos

( ) Outro.

4) Alguma empresa fornecedora de equipamentos eletrônicos pratica logística reversa?

( ) Não

( ) Sim.

Se sim, qual empresa:

5) Existe um depósito onde são armazenados os eletrônicos obsoletos e inservíveis?

( ) Sim

( ) Não

6) A 13를 CIA COM MEC possui um sistema de gerenciamento de resíduos eletrônicos?

( ) Sim

7) Se a sua resposta à questão anterior foi SIM, explique como é feito este gerenciamento, descrevendo como é feito o descarte do lixo eletrônico:

8) Durante um ano, quantas vezes os resíduos eletrônicos são encaminhados para o descarte?

( ) 1 a 2 vezes 
( ) 3 a 4 vezes

( ) mais de 5 vezes

9) Há uma estimativa da quantidade de lixo eletrônico descartado a cada ano?

( ) Sim

( ) Não

10) Se a sua resposta à questão anterior foi SIM, qual a quantidade de material eletrônico descartado?

11) Se o lixo eletrônico é encaminhado para empresas que recolhem este tipo de material, quais são essas empresas?

12) Com que freqüência é descartado os seguintes aparelhos (assinale com um X):

\begin{tabular}{|c|c|c|c|c|c|}
\hline & $\begin{array}{c}\text { Acada } 6 \\
\text { meseses }\end{array}$ & $\begin{array}{c}\text { Uma ve por } \\
\text { ano }\end{array}$ & $\begin{array}{c}\text { Acada } 2 \\
\text { anos }\end{array}$ & $\begin{array}{c}\text { Acadas } 5 \\
\text { anos }\end{array}$ & $\begin{array}{c}\text { Nēo costuma } \\
\text { ser } \\
\text { descartado }\end{array}$ \\
\hline \multicolumn{6}{|l|}{ Monitor } \\
\hline \multicolumn{6}{|l|}{ CPU } \\
\hline \multicolumn{6}{|l|}{ Impressora } \\
\hline \multicolumn{6}{|l|}{ Copiadora } \\
\hline \multicolumn{6}{|l|}{ Roteador } \\
\hline \multicolumn{6}{|l|}{$\begin{array}{c}\text { Tstabilizad } \\
\text { or }\end{array}$} \\
\hline \multicolumn{6}{|l|}{$\begin{array}{l}\text { Telefone } \\
\text { fixo }\end{array}$} \\
\hline \multicolumn{6}{|l|}{$\mathrm{TV}$} \\
\hline \multicolumn{6}{|l|}{ DVD } \\
\hline \multicolumn{6}{|l|}{ Notebook } \\
\hline $\begin{array}{c}\text { Tecladoe } \\
\text { mouse }\end{array}$ & & & & & \\
\hline
\end{tabular}

13) Quais as principais dificuldades encontradas na gestão dos resíduos eletrônicos? 